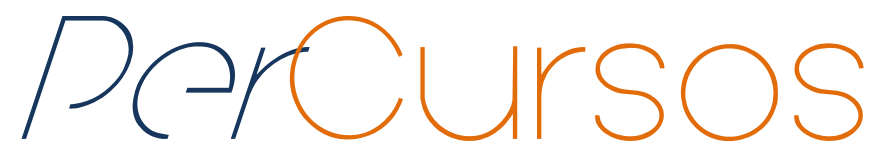

\title{
Serviço de extensão bibliotecária: do uso aos sentidos uma retrospectiva histórica
}

\begin{abstract}
Resumo
Trata de uma pesquisa bibliográfica de natureza exploratória que tem como objetivo apresentar uma reconstrução histórica conceitual do serviço de extensão bibliotecária desde o seu surgimento até a extinção do Instituto Nacional do Livro em 1990. Apresenta o conceito de extensão e categoriza os tipos de extensão realizados nas universidades, no setor agrícola e na biblioteca. Aborda os vários aspectos da extensão bibliotecária apontando como as bibliotecas realizam esse serviço e os recursos utilizados nas ações no sentindo da prestação de serviço, do estabelecimento de diálogo entre saberes e da construção compartilhada de conhecimento a partir de autores como Feitosa (1998), Dumont (1990), Fonseca (2005), Reis e Rezende (2005) e Suaiden (1979) que refletem sobre o serviço de extensão bibliotecária. Descreve as principais iniciativas para disseminação do serviço de extensão bibliotecária em âmbito mundial e nacional. Analisa como as bibliotecas ao longo do tempo no Brasil estão promovendo à democratização do acesso à informação para as comunidades periféricas por meio do serviço de extensão e nessa direção enfatiza as ações do Instituto Nacional do Livro (INL) para viabilizar a realização desse serviço apontando os diretores que tiveram iniciativas para priorizar esse serviço em suas gestões. Por fim, pontua os resultados percebidos com a realização do serviço no Brasil e sua implicação histórica para a atual situação desse serviço.
\end{abstract}

Palavras-chave: Biblioteca. Serviço de Extensão - Brasil. Serviço de Extensão Bibliotecária - Brasil.

\author{
Clara Duarte Coelho \\ Especialista em Docência \\ no ensino superior pelo Centro \\ Universitário Leonardo da Vinci. \\ Bibliotecária pela Universidade \\ Federal do Maranhão - Brasil. \\ clara_cell2@hotmail.com
}

\section{Valdirene Pereira da Conceição Doutora em Linguística pela Universidade Estadual Paulista Júlio de Mesquita Filho. \\ Bibliotecária pela Universidade Federal do Maranhão - Brasil. cvaldirene@bol.com.br}

\section{Para citar este artigo:}

COELHO, Clara Duarte; CONCEIÇÃO Valdirene Pereira da. Serviço de extensão bibliotecária: do uso aos sentidos uma retrospectiva histórica. Revista PerCursos. Florianópolis, v. 15, n.29, p. 57 - 78. jul./dez. 2014.

\section{DOI: $10.5965 / 1984724615292014057$}

http://dx.doi.org/10.5965/1984724615292014057 


\title{
Extension service librarian: use senses to a historical retrospective historical
}

\begin{abstract}
Is a bibliographic exploratory research that aims to present a conceptual historical reconstruction of the library extension service from its inception until the extinction of the National Book Institute in 1990. Presents the concept of extension and categorizes the types of extensions made in universities, in agriculture and in the library. Discusses the various aspects of library extension pointing how libraries perform this service and the features used in actions in feeling the provision of service, the establishment of dialogue between knowledge and the shared construction of knowledge from authors like Feitosa (1998), Dumont (1990), Fonseca (2005), Reis e Rezende (2005) and Suaiden (1979) to reflect on the service of library extension. Describes the main initiatives for the dissemination of library extension service worldwide and nationwide. Examines how libraries over time in Brazil are promoting the democratization of access to information for outlying communities through the extension service and this direction emphasizes the actions of the National Book Institute (INL) to enable the realization of this service pointing the directors who had to prioritize initiatives that service in their administrations. Finally, it highlights the perceived with the completion of the service results in Brazil and its historical implications for the current situation of service.
\end{abstract}

Keywords: Library. Extension Service - Brazil. Librarian Extension Service - Brazil. 


\section{Introdução}

A biblioteca tem sua trajetória marcada por restrições, e traz resquícios desse passado ao deixar de lado alguns segmentos sociais. O acesso à informação torna-se difícil em alguns locais sem a ajuda da biblioteca, que precisa ultrapassar o estigma de simples depósito de livros para espaço de transformação atuante na sociedade. Para que a biblioteca cumpra seu papel é imprescindível ter seus serviços planejados tanto para os usuários reais quanto para os potenciais, enfatizando a participação popular. Esse modelo de biblioteca ainda persiste distante para a realidade brasileira nos locais mais afastados das bibliotecas públicas onde a infraestrutura que garante $\mathrm{o}$ atendimento das necessidades básicas ainda é precária e, por conseguinte, o acesso à informação incide em um privilégio para poucos.

O acesso à informação não é visto como um direito nem pela população nem pelo poder público, logo cabe à biblioteca pensar formas de chegar a essa população excluída, pois a descontinuidade nas políticas culturais acarreta grandes prejuízos à população. Desse modo, compete às bibliotecas, por conta própria, pensarem nessa questão e a partir dos recursos disponíveis planejarem formas de atender à população menos favorecida.

O serviço de extensão bibliotecária que possibilita levar os serviços fixos da biblioteca aos locais mais remotos consiste em uma alternativa para alcançar o público mais distante das instalações físicas da biblioteca. Uma vez que o desenvolvimento de atividades extramuros é uma importante estratégia de atuação junto à comunidade, levar os serviços oferecidos diariamente na biblioteca para outros espaços não convencionais viabiliza despertar o interesse pela leitura, ampliando seu campo de atuação. Assim, o serviço de extensão seria a maneira mais eficaz de sanar os problemas relacionados às dificuldades de acesso a informação, mas de forma paliativa para que, no futuro, sejam pensadas políticas públicas para a implantação de bibliotecas que atendam de forma efetiva essa população. Diante desse contexto se faz necessária uma reflexão acerca do desenvolvimento desse serviço, pontuando as ações que colaboraram para o seu desenvolvimento. 
Nesta pesquisa serão apresentados os conceitos do serviço de extensão demonstrando que a reflexão e análise desse serviço são cruciais para que se tenha mais compreensão acerca do serviço de extensão proporcionando uma retrospectiva histórica tanto no Brasil como em âmbito mundial.

Partindo do interesse pessoal pelo lado social da biblioteca, de não só prestar serviços informacionais, mas também contribuir para a melhoria da sociedade surgiu o empenho em pesquisar o serviço de extensão e sua contribuição para o acesso à informação. Considera-se que a relevância deste estudo consiste em contribuir com a literatura sobre esse serviço já que em nossas pesquisas foram encontrados poucos estudos sobre essa temática.

O tipo de pesquisa adotado nessa empreitada foi a pesquisa bibliográfica, do ponto de vista da forma de abordagem do problema optou-se pela pesquisa exploratória. O percurso metodológico teve inicio pelo mapeamento de material bibliográfico e dos principais autores que tratam do assunto estudado para que confrontando as teorias desses autores possa ser delimitado o histórico do serviço de extensão bibliotecária desde a sua origem, perpassando pela sua inicialização no Brasil, até a extinção do Instituto Nacional do Livro em 1990. Quanto à construção do referencial teórico adotado sua fundamentação está baseada em autores como Feitosa (1998), Dumont (1990), Fonseca (2005), Reis e Rezende (2005), Suaiden (1979) que refletem sobre o histórico do serviço de extensão bibliotecária.

A primeira seção aborda a extensão e suas definições categorizando os tipos de extensão pontuando a sua aplicabilidade e o contexto de surgimento. Em seguida, investiga os aspectos históricos da prática da extensão a origem do serviço de extensão bibliotecária. A segunda seção discute e caracteriza o perfil do serviço de extensão da biblioteca. A terceira seção apresenta uma retrospectiva histórica do serviço de extensão bibliotecária destacando as principais iniciativas para implementação desde a sua origem em âmbito mundial perpassando pela aparição desse serviço nas gestões do Instituto Nacional do Livro até a extinção dessa instituição em 1990. Por último, apresentamos as conclusões alcançadas com o desenvolvimento da pesquisa. 


\section{0 universo da extensão: entre a teoria e a prática}

A palavra extensão definida como "efeito de estender" (FERREIRA, 2000, p. 307), possibilita diversas aplicações, como a extensão universitária, a agrícola e a bibliotecária, todas com a mesma finalidade de socializar algo aprendido por determinado grupo. $\mathrm{O}$ ato de realizar a extensão, ou seja, a ação extensionista vem sendo difundido como sinônimo de atendimento a comunidades que necessitam de algo que ainda não possuem, e parte da vontade de um determinado grupo para outro menos favorecido de técnicas e conhecimento, possibilitando assim a realização de uma ação. Aplicada a esse contexto, podemos extrair como características principais da extensão a prestação de serviço, o estabelecimento de diálogo entre saberes e a construção compartilhada de conhecimento.

Essa troca de saberes e experiências têm início com a extensão aplicada às universidades que resultante do confronto com a realidade regional possibilita a democratização do conhecimento produzido no âmbito acadêmico e a participação efetiva da comunidade na atuação da universidade, tem sua origem atribuída às universidades inglesas na segunda metade do século XIX, sendo elevada a um dos princípios norteadores das universidades, onde seus alunos oferecerem serviços que julgam úteis ao público que será atendido (FONSECA, 2005).

Logo após, surge à extensão agrícola no início de século XX estruturada com a participação de universidades americanas, consolidando pela primeira vez a extensão agrícola de forma institucionalizada (JONES; GARFORTH, 1997 apud PEIXOTO, 2008). No Brasil, a extensão agrícola se dá no período pós-guerra inspirado no modelo norte americano iniciando pelo estado de Minas Gerais, com o objetivo de modernizar a agricultura e a política de substituição das importações (PORTILHO, 1999).

A extensão agrícola é particularizada pela ação de agrônomos preocupados em modificar o modo de produção, inserindo novas tecnologias modificando as técnicas já habitualmente utilizadas pelos camponeses por meio de ações educativas. Esse conceito visa o contato direto com comunidades através da troca entre conhecimento científico e popular, instituída como ação educativa sistemática, onde o agrônomo utiliza palestras e 
outros recursos educacionais para conscientizar os agricultores sobre novos meios de cultivo da terra.

Entretanto, a ação extensionista independente da sua natureza é considerada por muitos autores como sendo invasiva. "A questão da extensão guarda uma série de ambiguidades e contradições, haja vista que de forma geral a mesma termina atuando de uma perspectiva assistencialista, servindo ao processo de manutenção da ordem social, legitimando-a" (REIS; RESENDE, 1995, p. 290), se não for realizada de forma participativa com a comunidade alvo da ação pode ocasionar a não aceitação do que está sendo passado ou a anulação completa dos saberes e experiências já adquiridos, acarretando assim prejuízos culturais à comunidade.

Tanto a extensão rural quanto a extensão universitária proporcionam o atendimento a pessoas consideradas excluídas, que sofrem com a ausência de políticas públicas que proporcionem melhores condições de vida. Porém não basta apenas oferecer um serviço sem ter público para usufruir, pois é imprescindível conhecer o alvo dessas ações e suas necessidades para que não seja apenas mais uma ação sem resultados. Como explica Freire (1983, p. 13) "a ação extensionista envolve qualquer que seja o setor em que se realize, a necessidade que sentem aqueles que a fazem, de ir até a outra parte do mundo, considerada inferior, para, à sua maneira normalizá-la. Para fazê-la mais ou menos semelhante a seu mundo".

Vista como uma ação dualista, essa pode tanto beneficiar quanto ocasionar malefícios àqueles que recebem a ação extensionista, por ignorar os conhecimentos populares impondo novas técnicas e saberes e muitas vezes utilizando linguagens que não são compreendidas, chegando a ser considerada como instrumento de dominação e não de esclarecimento como em seu conceito original. "Por isso, não podemos nos colocar na posição do ser superior que ensina um grupo de ignorantes, mas sim na posição humilde daquele que comunica um saber relativo a outros que possuem outro saber relativo" (FREIRE, 1979, p. 29). A população possui um saber que não pode ser ignorado, e deve ser trabalhada a troca entre os envolvidos e não a simples recepção das informações que forem passadas. 
Os intelectuais, os universitários, muitas vezes, sem o perceber, veem a população com que trabalham na condição de objeto e lamentavelmente perdem a oportunidade de enriquecer-se com o saber do outro, um saber diferente, mas, indiscutivelmente rico e portador da experiência do cotidiano (ROCHA, 2002, p. 169).

O conceito de extensão passou por desconstruções, sendo atualmente utilizado como uma relação de parceria o que resulta em extensão como processo de comunicação voltado para a cidadania valorizando a troca de saberes. Pensar um serviço de extensão requer um planejamento baseado em estudos sobre a comunidade que irá receber o serviço, uma vez que realizado de forma errônea não cumprirá seu propósito de proporcionar transformações tanto nos indivíduos atendidos quanto em quem promove a extensão.

Após a explicação dos conceitos que envolvem a extensão para melhor visualização o quadro 1 sintetiza a extensão e suas categorias:

Quadro 1-Categorias da extensão

\begin{tabular}{|l|l|l|}
\hline \multicolumn{1}{|c|}{ CATEGORIA } & \multicolumn{1}{|c|}{ DEFINIÇÃO } & \multicolumn{1}{|c|}{ OBJETIVO } \\
\hline $\begin{array}{l}\text { Extensão } \\
\text { Universitária }\end{array}$ & $\begin{array}{l}\text { Prestação de serviços para a } \\
\text { integração entre alunos e sociedade } \\
\text { buscando conciliar teoria e prática }\end{array}$ & Aprendizagem \\
\hline Extensão Agrícola & $\begin{array}{l}\text { Processo educativo de comunicação } \\
\text { de conhecimento técnico }\end{array}$ & Capacitação \\
\hline $\begin{array}{l}\text { Extensão } \\
\text { Bibliotecária }\end{array}$ & $\begin{array}{l}\text { Ação para levar às populações } \\
\text { distantes os serviços fixos da da } \\
\text { biblioteca }\end{array}$ & $\begin{array}{l}\text { Acesso } \\
\text { informação }\end{array}$ \\
\hline
\end{tabular}

Fonte: elaborado pelas autoras

O quadro possibilita uma comparação dos objetivos da extensão nos três conceitos que partem da mesma origem como prestação de serviço, mas com finalidades diferentes, incluindo a definição de extensão bibliotecária que será alvo deste estudo. Partindo para a extensão aplicada às bibliotecas, estas abandonaram sua postura de 
instituições fechadas para abrir seus serviços a todos que desejarem ter acesso e passou a utilizar o serviço de extensão como forma de se aproximar das comunidades mais distantes. Portanto, baseadas na estrutura da extensão agrícola, as bibliotecas dão início ao serviço de extensão bibliotecária saindo da postura passiva de esperar os usuários em seu espaço fixo para levar seus serviços a comunidades mais distantes fisicamente e a todos aqueles que se encontram impossibilitados de se deslocarem até as bibliotecas fixas, realizando assim atividades extramuros.

\subsection{Serviço de extensão bibliotecária: do conceito aos recursos utilizados}

A biblioteca transpôs diversas fases e sofre modificações constantes para atender de forma satisfatória seus usuários. Mostrar-se para a sociedade, consiste em princípio fundamental para os usuários utilizarem os serviços oferecidos, assim, sair do seu espaço físico e deslocar seus serviços preocupando-se com o público excluído tornou-se inquietação constante das bibliotecas.

Com a expansão urbana desordenada, fruto do desenvolvimento econômico, a população se depara com diversos problemas como a disparidade social, a violência e a desigualdade de acesso aos bens e serviços devido à falta de planejamento por parte do poder público, formando assim as periferias "os aglomerados distantes do centro [...] carentes de infraestrutura, onde passa a residir crescente quantidade de mão-de-obra necessária para fazer girar a maquinaria economia" (KOWARIC, 1993, p. 35 apud FEITOSA, 1998, p. 118). Por entender as condições difíceis da população para ter acesso à informação, as bibliotecas incutiram em suas ações a importância de oferecer seus serviços para aqueles que precisam da informação para lutar por seus direitos.

Nesse contexto, a visão elitista dessa instituição foi posta em contestação com a realização de ações extramuros para alcançar as comunidades periféricas como aponta Feitosa (1998, p. 66):

A biblioteca deve se desvencilhar de seu eterno papel de "guardiã" do acervo bibliográfico para abraçar causas sociais, lançando mão dos mais audaciosos meios de atingir o público ausente. Tais meios se estendem desde o mais completo e preciso balcão de informações dos mais 
variados tipos até o trabalho de extensão da biblioteca em comunidades carentes.

Esse cenário leva a refletir sobre o serviço de extensão que se insere como alternativa de complemento para os pontos fixos de uma biblioteca criando condições para que no futuro sejam implantados serviços fixos de biblioteca. Definido como:

Os processos e serviços que uma biblioteca leva a cabo para chegar aos seus utilizadores que, por razões de uma marginalização criada pelo contexto geográfico (relevo acidentado, existência de acidentes naturais difíceis de transpor, etc.) ou social onde se inserem, não podem fazer pleno uso dos seus serviços (CARRIÓN GÚTIEZ, 1993, p. 486 apud HENRIQUES, 2009, p. 31).

Diante da realidade das bibliotecas com poucos recursos tentando suprir lacunas deixadas pelo poder público que se exime da responsabilidade de oferecer meios para que a população tenha acesso à informação, o serviço de extensão por ter como principal característica a mobilidade, se adéqua a locais de grandes dimensões, como alternativa para amenizar as dificuldades de acesso a informação. De acordo com Suaiden (1995, p. 65):

O fato da biblioteca ser construída ou instalada no centro da cidade, o acesso a ela é facilitado apenas aos habitantes da zona urbana e, até hoje, a maioria das bibliotecas públicas não têm conseguido ampliar seu raio de atendimento às populações residentes na periferia, devido à falta de serviço de extensão bibliotecária.

Esse serviço seria a forma mais eficaz de atenuar os problemas relacionados ao acesso das comunidades mais distantes ao espaço da biblioteca. Conforme preconizou BRAY (1676 apud DUMONT, 1995a, p. 193)

Bibliotecas estáticas significarão pouco em países onde as pessoas necessitarão se locomover várias milhas a procura de um livro, mas bibliotecas que façam empréstimo e que cheguem até o leitor sem nenhuma cobrança, podem, satisfatoriamente, suprir as falhas de seus estudos até que um serviço permanente de livros seja implantado.

Esse serviço contribui para incluir aqueles que, por diversos motivos não podem frequentar a biblioteca ou simplesmente não tem interesse por desconhecer o papel 
dessa instituição. "Sua finalidade consiste em transformar não-leitores em leitores, criar e estimular o desejo pela boa leitura e reunir o livro ao leitor" (RANGANATHAN, 2009, p. 206). O serviço de extensão bibliotecária torna-se estratégia fundamental para atingir públicos com diversas dificuldades, garantindo assim a formação de leitores e futuros frequentadores das bibliotecas fixas, levando materiais bibliográficos e realizando os serviços presentes em uma biblioteca convencional, contribuindo para a democratização da informação por atender não apenas uma comunidade específica.

É nesse contexto político, econômico e social não muito favorável, que se desenvolve a ação do bibliotecário extensionista que atua diretamente em meio às camadas mais pobres da população. É um desafio, e é necessário estar consciente da situação e ser criativo, para se encontrar fórmulas que despertem o interesse dessa população pela leitura. (DUMONT, 1990, p. 30).

A biblioteca, conhecendo a realidade em que atua e o público que pretende atender, possibilita a escolha do recurso mais apropriado para a realização do serviço de extensão, considerando as circunstâncias e dificuldades que impedem que o usuário chegue até ela. Porém a vontade de receber deve vir dos membros da comunidade, não sendo apenas um serviço assistencialista definido sem a participação popular. Propor parcerias com pessoas do local atendido para coordenar o serviço de extensão é imprescindível para sua continuidade, pois garante maior comprometimento e interação entre biblioteca e os indivíduos envolvidos. Todo esse processo constitui-se, em uma ação social por incluir aqueles em situação econômica e socialmente degradante, não se restringindo apenas às comunidades distantes, mas também a prisões, hospitais, creches, asilos e outros lugares onde as pessoas, por situações específicas, não podem se deslocar ao local fixo da biblioteca.

Mediante os conceitos abordados a respeito do serviço de extensão bibliotecária a figura 1 apresenta uma síntese com alguns termos que individualizam essa prática: 
Figura 1 - Síntese dos conceitos do serviço de extensão bibliotecária

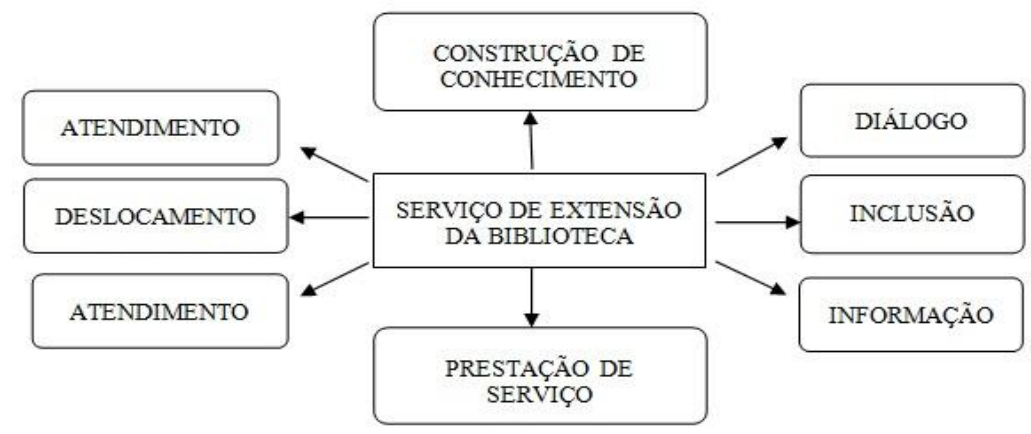

Fonte: elaborada pelas autoras

Entretanto, mesmo sendo reconhecidos os benefícios desse serviço, ele ainda é considerado um alto investimento para a realidade das bibliotecas que, na maioria das vezes contam com poucos recursos financeiros apenas para manutenção dos seus serviços fixos, e nem de recursos humanos suficientes para desenvolver esse tipo de serviço, o que impossibilita uma maior atuação da biblioteca.

Almeida Junior (2003, p. 31) critica o serviço de extensão por ser apenas mais um serviço da biblioteca sem grandes contribuições, onde ele coloca "que o serviço de extensão, entendido por muitos como atividades diferenciadas, não passam de deslocamento de acervo", o que leva a refletir sobre como é realizado esse serviço, avaliando se há contribuições desse serviço para o acesso à informação pelas comunidades periféricas. Deve-se pensar no serviço de extensão da biblioteca como algo paliativo para a implantação de futuras bibliotecas com serviços fixos, visto que o gosto pela leitura e a necessidade de informação já foram despertados e precisam ser sustentados. Como afirma Henriques (2009, p. 32):

Este tipo de serviços insere-se numa lógica de rede, ao servir de complemento dos pontos fixos de biblioteca já existentes preparando a sua criação em comunidades nas quais a sua existência ainda não se justifica num dado momento, ou ainda como forma de preparar e avaliar a possível necessidade de criação futura desse mesmo serviço fixo. 
O serviço de extensão da biblioteca utiliza recursos de acordo com a realidade que será atendida, avaliando as condições que pretende transpor e os recursos financeiros disponíveis para serem investidos. Cabe ao bibliotecário empregar os diversos recursos como as bibliotecas móveis, as circulantes e os ramais para realização do serviço de extensão para estimular a busca pela informação e o hábito da leitura. Dentre os recursos utilizados para realizar esse serviço podemos destacar:

a) carro-biblioteca, barco-biblioteca, moto-biblioteca e outros veículos;

b) caixa-estante - pequenas caixas de madeira, aço, malotes ou mesmo sacolas também chamada de biblioteca ambulante;

c) bibliotecas ramais e/ou sucursais.

Outro recurso pouco aproveitado pelas bibliotecas para a expansão dos serviços é a utilização de quiosques, como pontos de leitura e de empréstimo domiciliar de livros e outros materiais. Utilizar espaços públicos também faz parte das estratégias sugeridas para realizar o serviço de extensão através de programas de leitura em parques, estações de trem e/ou metrô, ou em espaços privados, como shopping centers. Espaços que serviriam para divulgar as bibliotecas, por conterem um grande fluxo de pessoas.

Entretanto, todos esses recursos citados são norteadores do serviço de extensão, onde cada biblioteca escolhe por meio de critérios estabelecidos pelos seus gestores aquele que mais se adapta à sua realidade e aos usuários que pretende atender e o que possibilita chegar até as comunidades mais afastadas da biblioteca central. "são inúmeras as opções, é só deixar a criatividade fluir e acontecer [...] É importante que [...] as atividades tragam informações interessantes e úteis, de acordo com as necessidades das comunidades atendidas [...]" (SOUSA, 2001, p. 38). O bibliotecário, de acordo com o interesse da comunidade, pode utilizar sua criatividade para desenvolver atividades que envolvam a leitura e a utilização de outros suportes informacionais visando também àqueles que não são alfabetizados.

É importante ressaltar que esse serviço consiste em estimulo para a comunidade receber uma biblioteca fixa ou para que acessem os serviços mais próximos de sua localidade, pois como informa Oliveira (1994, p. 137) sobre a origem do serviço de 
extensão bibliotecário "estes serviços de extensão, além de propagarem a informação para comunidades que não estavam no raio de ação das bibliotecas fixas, lançavam as bases para a sua futura instalação". Portanto, é necessário realizar atividades que despertem a vontade de obter informação e freqüentar o espaço da biblioteca. Fazer a reconstrução histórica desse serviço se faz necessária pra entender a sua difusão entre as bibliotecas, destacando a trajetória desse serviço tanto no Brasil como em âmbito mundial.

\section{Serviço de extensão bibliotecária: dimensão histórica}

Fazer uma afirmação da origem precisa do serviço de extensão torna-se tarefa difícil, pois existem muitos indícios desse tipo de atividade ao longo da história da humanidade com a utilização de carroças puxadas por cavalos para levar livros a quem precisava. Formalmente, com as características conhecidas hoje, o serviço de extensão data de três séculos. Como já mencionado, o serviço de extensão da biblioteca tem suas origens na prática extensionista agrícola compartilhando dos mesmos princípios de facilitar o acesso à informação através de ações educativas.

De acordo com estudos realizados por Fonseca (2005) e Henriques (2009) esse serviço tem origem na Inglaterra e nos Estados Unidos, simultaneamente, não podendo afirmar qual deles foi o pioneiro, sendo potencializado na década de 20 com o desenvolvimento do automóvel. Começa, portanto, “[...], fim do século XIX, início do século XX, uma ação bibliotecária extensionista, que se desenvolve com sucesso em países mais avançados e com expectativas diversas e muito tempo depois em países do terceiro mundo, inclusive no Brasil" (FONSECA, 2005, p. 54).

A iniciativa pioneira de prestação de serviços extensionistas de biblioteca, no Brasil data de 1936, quando Mário de Andrade esteve à frente do Departamento Municipal de Cultura de São Paulo, onde ofereceu destaque às bibliotecas incluindo-as nas políticas da administração pública para melhorar sua infraestrutura e propiciando a utilização de bibliotecas ambulantes como forma de aproximação entre livros e população, "um carro pequeno, com vitrines e sua pretensão era espalhar livros através de uma coleção 
circulante do automóvel-biblioteca" (DUMONT, 1995b, p. 194), ação considerada ousada para época, conforme relata Barbato (2004 apud HAAG, 2004, p. 83):

As bibliotecas ambulantes, que deveriam democratizar o acesso à leitura, chamadas de "loucura de menino" por Prestes Maia, para quem a iniciativa "oferecia romances policiais para os desocupados da Praça da República", [...] Em vez de livros e música, Maia queria gastar seu dinheiro com avenidas e pontes [...] Em 1938 Mário foi demitido.

Nos outros estados somente na década de 50 o serviço de extensão bibliotecária é iniciado por instituições como Serviço Social da Indústria (SESI) e Serviço Social do Comércio (SESC).

SESC e SESI, 1947 antecipam-se a estas, incorporando aos serviços de biblioteca a extensão, levando a comerciário e industriários, através de caixas-estantes e bibliotecas ambulantes, livros e informações diversas de lazer e recreação (FONSECA, 2005, p. 64).

Retrocedendo na história desse serviço no Brasil chegamos ao Instituto Nacional do Livro (INL) e suas políticas para valorização do livro e da biblioteca, criado na década de 30, momento em que o país passava por diversas transformações entre elas a inclusão da cultura nas políticas do governo, o INL que "visava à criação de um sistema nacional de bibliotecas, para coordenar e promover a modernização dos serviços bibliotecários” (PAIVA, 2008, p. 30), teve contribuição fundamental para implementação do serviço de extensão em vários municípios brasileiros. "O INL produziu políticas de bibliotecas públicas, mecanismos institucionais que facultavam o compartilhamento, a difusão e o uso da informação disponível para as comunidades" (OLIVEIRA, 1994, p. 17).

Dentre as gestões podemos aqui enfatizar os diretores que tiveram o serviço de extensão incluso em suas ações.

Quadro 2 - Diretores do INL preocupados com o serviço de extensão

\begin{tabular}{|c|c|c|}
\hline GESTOR & PERÍODO & AÇÕES \\
\hline Augusto Mayer & 1938 a 1953 & $\begin{array}{l}\text { - Implantação do projeto das } \\
\text { bibliotecas centrais com serviço de } \\
\text { extensão; } \\
\text { - Convênio entre o INL e as prefeituras; }\end{array}$ \\
\hline
\end{tabular}




\begin{tabular}{|c|c|c|}
\hline & & $\begin{array}{l}\text { - Extensão das ações das bibliotecas } \\
\text { através de caixas-estantes e bibliotecas } \\
\text { ambulantes. }\end{array}$ \\
\hline Umberto Pelegrino & 1967 a 1969 & $\begin{array}{l}\text { - Reestruturação do INL e criação de } \\
\text { bibliotecas municipais; } \\
\text { - Distribuição de livros para municípios } \\
\text { mais distantes; } \\
\text { - Promoveu a descentralização através } \\
\text { das bibliotecas volantes e das unidades } \\
\text { culturais. }\end{array}$ \\
\hline Maria Alice Barbosa & 1970 a 1974 & $\begin{array}{l}\text { - Criação do projeto de } \begin{array}{l}\text { serviços } \\
\text { bibliotecários para }\end{array} \\
\text { Transamazônica; } \\
\text { - Doação de carros-biblioteca e caixas- } \\
\text { estantes. }\end{array}$ \\
\hline Herberto Sales & 1974 a 1985 & $\begin{array}{l}\text { - Implantação do Sistema Estadual de } \\
\text { Bibliotecas Públicas (SEBP); } \\
\text { - Serviço de extensão ampliado para } \\
\text { hospitais, presídios e asilos. }\end{array}$ \\
\hline
\end{tabular}

Fonte: elaborado pelas autoras

Logo na primeira gestão do INL é possível identificar indícios desse serviço com o projeto idealizado por Augusto Mayer seu primeiro diretor, visando à implantação das bibliotecas centrais que teriam serviço de extensão para descentralizar seus serviços, projeto que por motivos financeiros não foi colocado em prática. No entanto, essa seria considerada a iniciativa pioneira de preocupação com as comunidades mais afastadas, não podendo ser efetivada por questões também sociais de uma população ainda não habituada à leitura e a ausência de profissionais qualificados para gerir essas bibliotecas. Contudo, mesmo em outros projetos desenvolvidos por Mayer como o convênio entre o INL e as prefeituras para criação de bibliotecas, o serviço de extensão estava presente, estreitando os laços entre usuário e biblioteca, como afirma Oliveira (1994, p. 69):

Ainda que a proposta do convênio fosse muito semelhante ao trabalho cooperativo desenvolvido durante o Estado Novo, havia uma clara diferença na ação do INL. Refletindo o fim do regime ditatorial e a progressiva redução do controle estatal sobre a sociedade, a cultura 
oficial deixava de ser imposta à biblioteca pública e ela passava a reconhecer e acolher as múltiplas manifestações culturais produzidas pelas comunidades. Através da coleta de informações para o processo de seleção e da abertura para a comunidade.

À frente do INL de 1967 a 1969 Umberto Pelegrino teve como objeto de ação a descentralização para melhor utilização dos recursos disponíveis. Paiva (2008, p. 34) explica que em suas propostas de mudança:

Ainda que muito modestamente, a descentralização promoveu algumas mudanças nos modelos de bibliotecas públicas, que podem ser exemplificados em duas novas propostas: as bibliotecas volantes e as unidades culturais. As bibliotecas volantes, com veículos adaptados, que já haviam sido utilizadas nas décadas de 1930 e 1950, visavam causar um impacto, com a presença inesperada em diferentes pontos de algumas cidades (Rio de Janeiro, Brasília e Natal). Acreditava-se que bastaria o acesso momentâneo para motivar os leitores. Desconsiderava-se a alta taxa de analfabetismo e os gostos e necessidades dos possíveis usuários.

É perceptível, na gestão de Pelegrino, a preocupação em melhorar os serviços oferecidos pelas bibliotecas, através da descentralização e criação de comissões regionais, dividindo melhor os recursos disponíveis, mas os altos custos dos serviços inviabilizaram manter suas ações em funcionamento.

Durante a gestão de Maria Alice Barbosa de 1970 a 1974, suas ações foram voltadas para a biblioteca escolar, mas sem esquecer a implantação de bibliotecas e salas de leitura para atender e facilitar o acesso da população ao livro. Maria Alice deu continuidade às medidas já implantadas na gestão de Humberto Pelegrino, elaborando um projeto de serviços bibliotecários para a região Transamazônica, "que dotou a região de cinco carros-biblioteca, pelo menos 17 mil livros, dezenas de caixas-estantes e salas de leitura" (PAIVA, 2008, p. 37). Projeto esse que não teve continuidade e os materiais distribuídos foram extraviados. As doações de carros-biblioteca e caixas-estantes para outros estados foram constantes durante o tempo em que ela ficou à frente do INL obtendo bastante sucesso ao final de sua gestão.

Na gestão de Herberto Sales 1974 a 1985 apesar de seu caráter voltado para biblioteca como guardião da memória, "relegando ao segundo plano suas possibilidades 
como agência de informação a serviço da população" (OLIVEIRA, 1994, p. 124), as bibliotecas através do Sistema Estadual de Bibliotecas Públicas (SEBP) ofereceram recursos técnicos e humanos para o funcionamento das bibliotecas municipais.

Foram oferecidos às comunidades os serviços tradicionais de consulta, empréstimo; serviço de extensão através de carros-biblioteca, caixas estantes; apoio a atividades de leitura dos alunos que não dispunham de bibliotecas escolares, aos planos de alfabetização e educação de adolescentes e adultos e colaboração com sistemas de informação em ciência e tecnologia (OLIVEIRA, 1994, p. 129).

Em sua gestão, o serviço de extensão foi ampliado utilizando carros-biblioteca e as caixas-estantes também para levar os serviços da biblioteca a lugares como hospitais, presídios e asilos.

O serviço de extensão enfrentou diversos obstáculos para ser posto em prática principalmente pela falta de continuidade nas políticas públicas e o acanhado orçamento destinado para as bibliotecas, mas obteve sucesso no Brasil em virtude das parcerias entre as universidades federais e o INL, com a doação de carros-biblioteca onde os cursos de Biblioteconomia tomaram a frente para viabilizar a concretização desse serviço. Outro ponto a ser destacado é a participação das bibliotecas públicas que tiveram seus serviços ampliados permitindo uma maior atuação nos lugares mais afastados da biblioteca central. Algumas das ações idealizadas pelo INL ainda estão em funcionamento como é o caso do Carro-Biblioteca da Universidade Federal de Minas Gerais que ainda está em plena atividade sob a responsabilidade do Curso de Biblioteconomia.

Ao longo de todas as gestões as bibliotecas passaram por processo de transição para um modelo mais preocupado com a disseminação da informação, considerando a comunidade como parte envolvida nos serviços oferecidos, sendo prática constante a doação de bibliotecas móveis para os municípios brasileiros, mas também incentivando a compra de carros-biblioteca pelos estados e municípios, a doação de livros e a capacitação de profissionais para atuarem nesse segmento.

Na década seguinte após ser incorporado a Fundação Nacional Pró-Leitura o Instituto Nacional do Livro foi extinto em 1990. “Assim, através de um documento em 
que sequer figurava a sua sigla, é extinta a maior instituição governamental diretamente ligada ao livro, à leitura e às bibliotecas públicas na história do País, após 52 anos de existência: o INL" (PAIVA, 2008, p.71). Fato que marcou de forma negativa o progresso das bibliotecas públicas e a realização do serviço de extensão bibliotecária.

Essa alternativa muito utilizada até hoje, por facilitar o acesso e a inclusão das comunidades mais afastadas do espaço físico da biblioteca, vem sendo realizada de forma ampla apesar da pouca literatura disponível sobre esse serviço. Suaiden (1979, p. 26-27) já fazia referência a esse serviço ao afirmar em suas pesquisas que "o ato de levar livro às populações menos favorecidas é fundamental num país como o Brasil, com um número muito grande de analfabetos e um percentual baixo de pessoas com hábito de leitura". Conhecer o histórico desse serviço proporciona aos bibliotecários, profissionais da informação e governo perceberem as principais falhas e sucessos para estabelecer políticas públicas de informação mais consistentes, pois são iniciativas para fomentar o hábito da leitura que irão despertar a população para que esta saiba do que está sendo afastada e cobre a implantação de bibliotecas públicas de qualidade e acesso a informação.

\section{Conclusões}

Sabe-se da importância da biblioteca para o desenvolvimento da sociedade, mas seus produtos e serviços ainda são pouco divulgados, e sua atuação tímida prejudica a mudança da imagem construída ao longo do tempo, de instituição apenas para guardar e preservar os livros, ignorando o acesso à informação e à leitura. Na atual sociedade a biblioteca disputa lugar com os meios de comunicação e as novas tecnologias agravantes da exclusão social.

O acesso à informação é restrito a quem tem poder aquisitivo, o que amplia a responsabilidade da biblioteca que deve incluir em suas ações a inclusão social, direito básico da população renegado pelo poder público. Em um país com as dimensões geográficas do Brasil, às condições econômicas, e o descaso do poder público diante das 
bibliotecas se torna inviável as poucas bibliotecas existentes atenderem com seus serviços fixos a grande demanda de locais que não possuem biblioteca.

Viu-se que o serviço de extensão é o meio mais eficaz para amenizar as lacunas deixadas pela ausência de bibliotecas nos bairros mais distantes do centro da cidade por ter como marca a mobilidade independente das limitações geográficas ou a não possibilidade de se deslocar até a biblioteca, pois mesmo afastados os moradores dessas comunidades precisam de informação para reivindicar seus direitos e modificar sua realidade, o que é previsto em constituição e não respeitado, violando a participação desses sujeitos na construção da democracia.

Mediante essa realidade se faz necessário investigar a trajetória do serviço de extensão bibliotecário pontuando as iniciativas para o seu fomento conhecendo as políticas de incentivo do poder público. O serviço de extensão bibliotecária tem sua origem simples e ao mesmo tempo inexata, mas repleta de dificuldades e no Brasil não foi diferente, pois há um histórico de políticas públicas descontinuadas e sem apoio do poder público gerando um atraso na sua disseminação no país. Entre elas destaca-se a pioneira de Mario de Andrade em São Paulo e em seguida nos outros estados a da iniciativa privada por meio do Serviço Social do Comércio e do Serviço Social da Indústria que marcaram o inicio da utilização desse serviço, sendo que a primeira não obteve êxito por não contar com o apoio do então presidente, o que mostra o desprestigio das bibliotecas no âmbito do poder público.

Dentre as instituições que adotaram a realização do serviço de extensão bibliotecária o Instituto Nacional do Livro (INL) em âmbito nacional tem grande importância, pois o serviço de extensão bibliotecária esteve presente em muitas de suas gestões com políticas públicas de estímulo para suprir a questão da ausência das bibliotecas fixas. Durante todas as suas gestões foi posto em pauta, entretanto por falta de estrutura financeira foram poucos os projetos que obtiveram êxito.

Percebe-se que o serviço de extensão das bibliotecas, tem sido utilizado de forma acanhada sem um propósito definido, o que corre o risco do serviço perder seu sentido principalmente pela ausência do poder público, mas por haver uma realidade 
preocupante com pessoas excluídas do âmbito informacional o serviço de extensão tem um cenário bastante amplo para atuar. Somente disponibilizar leituras para o lazer não é suficiente, é preciso intervir na vida da comunidade, trazendo para utilizar o serviço de extensão aqueles que estão afastados da educação formal, assim como aqueles que não são alfabetizados, trabalhando outros recursos informacionais que não só o escrito.

É preciso manter a realização desse serviço, mas rever o planejamento se torna imprescindível para obter resultados mais completos na formação de leitores e por consequência público frequentador da biblioteca. O serviço de extensão diminui a distância entre usuário e biblioteca, entretanto a realização desse serviço não exime do poder público o dever de construir bibliotecas públicas ou a criar bibliotecas comunitárias, que seriam a solução para o problema de acesso à informação das comunidades periféricas. Como foi pontuado o poder público tem grande parcela de contribuição nessa questão e instituições como o Instituto Nacional do Livro precisam ser criadas para estimular a autonomia das bibliotecas e gerir politicas públicas direcionadas aos livros e as bibliotecas.

O que foi constatado após rever a trajetória do serviço de extensão tanto no Brasil, quanto em âmbito mundial é um cenário inerte em que as bibliotecas sobrevivem com políticas descontinuadas e com livros que nem sempre interessam ao público que será atendido. Portanto o serviço de extensão tem um futuro muito longo, a idéia de oferecer estrutura para que sejam implantadas bibliotecas para constituir uma rede de serviços que trabalhem em sistema de cooperação ainda é uma realidade distante, pois as descontinuidades nas políticas públicas de informação representam um atraso na democratização da informação.

\section{Referências}

ALMEIDA JUNIOR, Oswaldo Francisco de. Sociedade e biblioteconomia. São Paulo: Polis, 1997.

DUMONT, Lígia Maria Moreira. A ação do carro-biblioteca ou o desafio de se incentivar o gosto pela leitura em comunidades de baixa renda. Revista da Escola de Biblioteconomia da UFMG, Belo Horizonte, v. 19, n. 1, p. 24-38, mar. 1990. 
- Carro-biblioteca e leitura no Brasil: um binômio inseparável. Revista da Escola de Biblioteconomia da UFMG, Belo Horizonte, v. 24, n. 2, p. 192-205, jul. / dez. 1995 . . A extensão através do carro biblioteca. Revista da Escola de Biblioteconomia da UFMG, Belo Horizonte, v. 24, n. 2, p. 182-191, jul./ dez. 1995b

FEITOSA, Tadeu Luiz. O poço da draga: a favela e a biblioteca. São Paulo: Annablume, 1998.

FERREIRA, Aurélio Buarque de Holanda. Miniaurélio século XXI escolar: o minidicionário da língua portuguesa. Rio de Janeiro: Nova Fronteira, 2000.

FONSECA, Maria Clara. Biblioteca pública: da extensão à ação cultural como prática de cidadania. 2005. 209 f. Dissertação (Mestrado em Ciência da Informação)-Pontifícia Universidade Católica de Campinas, Campinas, 2005.

FREIRE, Paulo. Extensão ou comunicação?. Rio de Janeiro: Paz e Terra, 1983.

. Educação e mudança. Rio de Janeiro: Paz e Terra, 1979.

FUNDAÇÃO BIBLIOTECA NACIONAL. Biblioteca Pública: princípios e diretrizes. Rio de Janeiro, 2000.

HAAG, Carlos. Da teoria à prática: a história do Departamento de Cultura de Mário de Andrade. Rev. Pesquisa FAPESP, São Paulo: n. 106, p. 82-85, dez. 2004. Disponível em: < http://revistapesquisa.fapesp.br/2004/12/01/da-teoria-a-pratica-2/ >. Acesso em: 20 out. 2011

HENRIQUES, João Carlos Ribeiro. Na estrada com os livros: as bibliotecas móveis como solução de acesso a serviços de biblioteca num país de contrastes. 2009. $196 \mathrm{f}$. Dissertação (Mestrado em Ciências da Informação e da Documentação)-Universidade Nova de Lisboa, Lisboa, 2009.

OLIVEIRA, Zita Catarina Prates de. A biblioteca "fora do tempo": políticas governamentais de bibliotecas públicas, 1937-1989. 1994. 221 f. Tese (Doutorado em Ciências da Comunicação)-Universidade de São Paulo, São Paulo, 1994.

PAIVA, Marília de Abreu Martins de. Bibliotecas públicas: políticas do estado brasileiro de 1990 a 2006. 2008. 140 f. Dissertação (Mestrado em Ciência da Informação)-Universidade Federal de Minas Gerais, Belo Horizonte, 2008.

PEIXOTO, Marcus. Extensão rural no Brasil: uma abordagem histórica da legislação. Brasília: CONLEG, 2008, 50 p. Disponível em: 
<http://www12.senado.gov.br/publicacoes/estudos-legislativos/tipos-de-estudos/textospara-discussao/td-48-extensao-rural-no-brasil-uma-abordagem-historica-da-legislacao >. Acesso em: 17 maio. 2011.

PORTILHO, Maria Sibele Brasiliense. Extensão rural e prática educativa informal. Educação e Filosofia, Uberlândia, v. 13, n. 26, p. 129-140, jul./dez. 1999.

RAGANATHAN, Shiyali Ramamrita. As cinco leis da biblioteconomia. Brasília, DF: Brinquet de Lemos, 2009.

REIS, Alcenir Soares dos; REZENDE, Marlene Edite Pereira de. Escutando a comunidade: em discussão a extensão junto às camadas populares. Revista da escola de Biblioteconomia da UFMG, Belo Horizonte, v. 24, n. 2, p. 289-312, jul/ dez. 1995

ROCHA, Roberto Mauro Gurgel. Extensão universitária e saber popular. In: MELO NETO, José Francisco de (org.). Extensão universitária: diálogos populares. João Pessoa: EDUFBA, 2002. p. 163-177.

SUAIDEN, Emir José. Biblioteca pública brasileira: desempenho e perspectivas. 1979. 103 f. Dissertação (Mestrado em Biblioteconomia)-Universidade Federal da Paraíba, João Pessoa, 1979. 